\title{
Pumpkin Yield Affected by Soil Nutrients and the Interactions of Nitrogen, Phosphorus, and Potassium Fertilizers
}

\author{
Yang Chen \\ Agricultural Bio-resources Research Institute, Fujian Academy of Agricultural \\ Sciences, Fuzhou, Fujian, 350003, China
}

\author{
Xianzhi Zhou \\ Agricultural Bio-Resources Research Institute, Fujian Academy of Agricultural \\ Sciences, Fuzhou 350003, China; and Fuzhou Tropical Crop Scientific \\ Observation Experimental Station of Ministry of Agriculture and Rural \\ Affairs, Fuzhou 350003, China
}

\section{Yongsheng Lin and Lina Ma \\ Agricultural Bio-resources Research Institute, Fujian Academy of Agricultural Sciences, Fuzhou, Fujian, 350003, China}

Additional index words. Cucurbita maxima, equation, fertilizer performance nitrogen, phosphorus, potassium, "3414" scheme

\begin{abstract}
To study the effects of nitrogen (N), phosphorus (P), and potassium (K) fertilizers on the yield of 'Jianbao' pumpkin (Cucurbita maxima Duch), we conducted experiments using the "3414" optimal design scheme in Dehua County, Quanzhou, Fujian, China. Overall, three fertilizer factors $(N, P, K)$ were tested with four fertilization levels (level 0 , no fertilizer; level 1, 0.5-times the typical fertilizing amount; level 2, typical fertilizer application; level 3, 1.5-times the typical application), with a total of 14 different fertilization treatments. Based on the results of this study, a corresponding fertilization performance model was established to provide a practical basis for ensuring highly efficient cultivation of pumpkin in the field. Our results showed that the experimental data could not be fitted with a ternary quadratic polynomial fertilizer model, but that it could be fitted with a single-variable quadratic fertilizer model. According to the fitted model, pumpkin yield first increased and then decreased with the increasing amount of $\mathbf{N}$, $P$, and $K$ used. We identified significant regression relationships between 'Jianbao' pumpkin yield and the amount of $N, P$, and $K$ in the fertilizer. Finally, based on the singlevariable quadratic fertilizer model, we suggest that the quantities of $N, P$, and $K$ fertilizer used for growing 1 ha of 'Jianbao' pumpkin should be 390.5, 213.8 , and $371.3 \mathrm{~kg}$, respectively.
\end{abstract}

Pumpkin, which originated in America, is one of the first vegetables that was cultivated in China (Wang, 2002). Pumpkin possesses a unique flavor and is rich in vitamins, minerals, sugars, protein, and cellulose. It is an important food source of adjuvants that have beneficial roles in the treatment of diabetes, hepatitis, cirrhosis, and kidney disease. Therefore, pumpkin is widely favored as a healthy, natural food in recent years (Wang, 2002).

The area of pumpkin cultivation in China has been continually increasing; in 2013, the total cultivation area and yield of pumpkin had reached nearly $4000 \mathrm{~km}^{2}$ and 7 million

\footnotetext{
Received for publication 19 Apr. 2019. Accepted for publication 8 July 2019 .

This research was supported by Fujian Provincial Public Welfare Research Project (2018R1017-5).

Y.C. and X.Z. are the corresponding authors. E-mail: 258269673@qq.com or xianzhizhou@ 126.com.
}

tons, respectively. China is now the largest producer of pumpkin in the world (Yang et al., 2016). Cucurbita moschata, C. maxima, and C. pepo are the three major species of pumpkins cultivated in China (Chu et al., 2007). A rational fertilization strategy is key to achieving vegetables with high quality and high yield. As such, multiple studies have been conducted in the field of fertilization technology to cultivate pumpkin. The study by Liu et al. (2014) showed that changing the ratio of water and $\mathrm{N}$ in the fertilizer had a significant effect on root growth, yield, and water-N use efficiency during C. moschata cultivation; they found that the optimum combination of water and $\mathrm{N}$ for growing C. moschata was achieved with an irrigation rate of $1100 \mathrm{~m}^{3} \cdot \mathrm{ha}^{-1}$ and an $\mathrm{N}$ application rate of $250 \mathrm{~kg} \cdot \mathrm{ha}^{-1}$. Li et al. (2013) used a balanced fertilization technique during their study of pumpkin. They found that balancing the amounts of $\mathrm{N}, \mathrm{P}$, and $\mathrm{K}$ in the fertilizer could improve pump- kin yield considerably. Huang et al. (2006) studied the effects of $\mathrm{K}$ fertilizer on the yield of C. moschata in a solar greenhouse and found that the application of $\mathrm{K}$ fertilizer at 81 $\mathrm{kg} \cdot \mathrm{ha}^{-1}$ was ideal for obtaining an optimal pumpkin yield. Although considerable fertilization techniques for pumpkin cultivation achievements have been created, only a limited number of fertilization strategies are available. In addition, considering the effects of both $\mathrm{N}$ and $\mathrm{K}$ fertilizers, further research of the aspects of fertilizer requirements, fertilization effects, and fertilization equations are needed for optimal pumpkin cultivation in China.

Soil testing is an environment-friendly technique of determining fertilizer recommendations. Specifically, the appropriate quantity, period, and method of application of $\mathrm{N}, \mathrm{P}$, and $\mathrm{K}$ fertilizers have been proposed based on plant fertilizer requirements, soil fertility performance, and fertilizer effects (Han and Zhang, 2014; Wang et al., 2002; Zhang et al., 2016). To date, soil testing and fertilizer recommendation techniques have been used for the cultivation of several different crops such as rice (Li et al., 2017; Mao et al., 2014), corn (Chai et al., 2014; Gao et al., 2018; Wang et al., 2018), soy (Sun et al., 2013), wheat (Sun et al., 2009), and rapeseed (Yang et al., 2011). These techniques have also been used for the cultivation of fruits such as pear (Chai et al., 2013) and Chinese herbs such as honeysuckle (Zeng et al., 2017). However, no study has evaluated the effectiveness of soil testing and fertilizer recommendation techniques in the context of pumpkin cultivation. To determine the optimal fertilizer ratio required for ensuring high pumpkin yields, we designed experimental tests based on the "3414" scheme [three fertilizer factors (N, P, K), four fertilization levels, and 14 types of proportional fertilization treatments]. Previously, Wang et al. (2002) performed a study of the 'Jianbao' pumpkin, C. maxima, bred by the Agricultural Bio-resources Research Institute of the Fujian Academy of Agricultural Sciences. Our aim was to explore the effects of varying the ratios of $\mathrm{N}, \mathrm{P}$, and $\mathrm{K}$ in the fertilizer on pumpkin yield.

\section{Materials and Methods}

Experimental materials. The 'Jianbao' pumpkin cultivar C. maxima (Fujian certification number: 2016002) cultivated by the Agricultural Bio-resources Research Institute of the Fujian Academy of Agricultural Sciences was used as the study material. The $\mathrm{N}$, $\mathrm{P}$, and $\mathrm{K}$ fertilizers used during the study were urea $(\mathrm{N} \geq 46 \%$; China BlueChemical Ltd., Dongfang, Hainan Province, China), superphosphate $\left(\mathrm{P}_{2} \mathrm{O}_{5} \geq 12 \%\right.$; Xiamen Xiahua Industrial Co. Ltd., Xiamen, Fujian Province, China), and potassium sulfate $\left[\mathrm{K}_{2} \mathrm{O} \geq\right.$ 50\%; Qingshang Chemical (Xiamen) Co. Ltd, Xiamen, Fujian Province, China], respectively.

Experimental method. The experiment was performed using the Longxun vegetable base in Dehua County, Quanzhou, Fujian, 
between April and Aug. 2018. During the experiment, the temperature ranged from 10.5 to $34.7{ }^{\circ} \mathrm{C}$, with a cumulative precipitation of $1100.8 \mathrm{~mm}$. The experimental field had a flat terrain with sandy-loamy soil. The following physical and chemical properties were measured in the soil: $\mathrm{pH}$ (5.1), organic matter content (21 $\left.\mathrm{g} \cdot \mathrm{kg}^{-1}\right)$, alkaline $\mathrm{N}$ content $\left(100 \mathrm{mg} \cdot \mathrm{kg}^{-1}\right)$, effective $\mathrm{P}$ content $\left(19.5 \mathrm{mg} \cdot \mathrm{kg}^{-1}\right)$, and available $\mathrm{K}$ content (28 mg. $\left.\mathrm{kg}^{-1}\right)$. Based on the "3414" optimal design scheme, as recommended by the Ministry of Agriculture of China, the experiment was designed to include three elements $(\mathrm{N}$, $\mathrm{P}$, and $\mathrm{K}$ ) at four different application levels or treatments. Of the four treatments, level 2 represents the locally recommended quantity of fertilizers applied. The quantity of fertilizers applied at levels 0,1 , and 3 were no fertilizer, 0.5-times the amount applied at level 2, and 1.5times the amount applied at level 2 (as shown in Table 1). Fourteen different treatments were designed, as shown in Table 2. The experiment was repeated three times for each treatment using a random experimental block design. Each experimental block had a trench with a width of $1.6 \mathrm{~m}$ and a length of $15 \mathrm{~m}$, respectively. We planted the pumpkins in a single row $70 \mathrm{~cm}$ apart. Each block was planted with 22 pumpkins, with 9000 pumpkins planted per hectare. We planted the pumpkins with single vine pruning on a "Y"-shape bracket. The branches of the plants were configured in a "Y"-shape cross pattern in the front, but in an oblique cross pattern on the side. The pumpkin vines were guided to climb up a rack covered with nylon mesh. The pumpkins were sown on 2 Apr. 2018. Approximately 1000 full and mature seeds of the 'Jianbao' were first soaked in $55^{\circ} \mathrm{C}$ warm water for $15 \mathrm{~min}$, and then in pure water for $5 \mathrm{~h}$. Then, the seeds were wrapped with sterile gauze and placed in an incubator at $30^{\circ} \mathrm{C}$ for germination for $\approx 48 \mathrm{~h}$. Seeds that sprouted were placed in plug trays for seedling cultivation. The seedling substrate $(\mathrm{pH}=6.3$; organic matter content $=$ $49.5 \mathrm{~g} \cdot \mathrm{kg}^{-1}$; alkaline $\mathrm{N}$ content $=670.6 \mathrm{mg} \cdot \mathrm{kg}^{-1}$; effective $\mathrm{P}$ content $=380.5 \mathrm{mg} \cdot \mathrm{kg}^{-1}$; and available $\mathrm{K}$ content $=4623.5 \mathrm{mg} \cdot \mathrm{kg}^{-1}$ ) was purchased from Fujian Chaoda Xiyuan Bio-organic Fertilizer Co., Ltd. After the seedlings reached the stage of three leaves and one terminal bud, they were transplanted on 22 Apr. 2018. Spraying was performed twice during the seedling period. Before planting, a mixture of N-P-K fertilizers $(50 \% \mathrm{~N}, 50 \% \mathrm{~K}$, and $100 \% \mathrm{P}$ fertilizer) (Table 2) was used in each furrow. During the rosette stage, an additional fertilizer mix $(20 \% \mathrm{~N}$ and $20 \% \mathrm{~K}$ fertilizer) (Table 2) was applied to the field $20 \mathrm{~cm}$ away from the plants using the hole fertilization technique. During the fruiting period, when fruits reached the size of a hen egg, a mix of N-K fertilizers $(30 \% \mathrm{~N}$ and $30 \% \mathrm{~K}$ fertilizer) (Table 2) was applied $20 \mathrm{~cm}$ away from the plants using hole fertilization. Conventional field management practices for pumpkin cultivation were followed.

Harvesting and production. During pumpkin harvest, the lateral diameter $(\mathrm{cm})$, longitudinal diameter $(\mathrm{cm})$, single fruit weight $(\mathrm{kg})$, number of fruits per plant, and the yield per block (tons.ha ${ }^{-1}$ ) were measured and recorded.

Data analysis. The " 3414 " test analyzer (SG-2.3, soil testing formula fertilization data management system; National Agricultural Technology Extension Service Center of the Plantation Management Department of the Ministry of Agriculture, Beijing, China), statistical software (DPS 7.05; Tang, 2005), and MS Excel (Microsoft Co., Ltd., Beijing, China) were used for data analysis. The difference between group means was analyzed using the least significant difference method. Based on the ratios of $\mathrm{N}, \mathrm{P}$, and $\mathrm{K}$ fertilizers and the 'Jianbao' pumpkin yield, statistical analyses were performed by fitting the relationship between the two parameters using singlevariable quadratic and a ternary quadratic polynomial fertilizer models. The maximum yield and corresponding optimum amounts of $\mathrm{N}$, $\mathrm{P}$, and $\mathrm{K}$ fertilizers were subsequently calculated using these two models.

Table 1. Experimental fertilizer treatments using four different application levels for 'Jianbao' pumpkin.

\begin{tabular}{lccc}
\hline Level & N fertilizer $\left(\mathrm{kg} \cdot \mathrm{ha}^{-1}\right)$ & P fertilizer $\left(\mathrm{kg} \cdot \mathrm{ha}^{-1}\right)$ & $\mathrm{K}$ fertilizer $\left(\mathrm{kg} \cdot \mathrm{ha}^{-1}\right)$ \\
\hline 0 & 0 & 0 & 0 \\
1 & 150 & 75 & 150 \\
2 & 300 & 150 & 300 \\
3 & 450 & 225 & 450 \\
\hline
\end{tabular}

Table 2. Fourteen different experimental fertilizer treatments based on the "3414" optimal design scheme (Wang et al., 2002) for 'Jianbao' pumpkin.

\begin{tabular}{ccccc}
\hline Experimental treatment & Fertilizer combination & $\mathrm{N}\left(\mathrm{x}_{1}\right)$ & $\mathrm{P}\left(\mathrm{x}_{2}\right)$ & $\mathrm{K}\left(\mathrm{x}_{3}\right)$ \\
\hline 1 & $\mathrm{~N}_{0} \mathrm{P}_{0} \mathrm{~K}_{0}$ & 0 & 0 & 0 \\
2 & $\mathrm{~N}_{0} \mathrm{P}_{2} \mathrm{~K}_{2}$ & 0 & 2 & 2 \\
3 & $\mathrm{~N}_{1} \mathrm{P}_{2} \mathrm{~K}_{2}$ & 1 & 2 & 2 \\
4 & $\mathrm{~N}_{2} \mathrm{P}_{0} \mathrm{~K}_{2}$ & 2 & 0 & 2 \\
5 & $\mathrm{~N}_{2} \mathrm{P}_{1} \mathrm{~K}_{2}$ & 2 & 1 & 2 \\
6 & $\mathrm{~N}_{2} \mathrm{P}_{2} \mathrm{~K}_{2}$ & 2 & 2 & 2 \\
7 & $\mathrm{~N}_{2} \mathrm{P}_{3} \mathrm{~K}_{2}$ & 2 & 3 & 2 \\
8 & $\mathrm{~N}_{2} \mathrm{P}_{2} \mathrm{~K}_{0}$ & 2 & 2 & 0 \\
9 & $\mathrm{~N}_{2} \mathrm{P}_{2} \mathrm{~K}_{1}$ & 2 & 2 & 1 \\
10 & $\mathrm{~N}_{2} \mathrm{P}_{2} \mathrm{~K}_{3}$ & 2 & 2 & 3 \\
11 & $\mathrm{~N}_{3} \mathrm{P}_{2} \mathrm{~K}_{2}$ & 3 & 2 & 2 \\
12 & $\mathrm{~N}_{1} \mathrm{P}_{1} \mathrm{~K}_{2}$ & 1 & 1 & 2 \\
13 & $\mathrm{~N}_{1} \mathrm{P}_{2} \mathrm{~K}_{1}$ & 1 & 2 & 1 \\
14 & $\mathrm{~N}_{2} \mathrm{P}_{1} \mathrm{~K}_{1}$ & 2 & 1 & 1 \\
\hline
\end{tabular}

\section{Effects of different fertilization interactions on pumpkin size and yield}

As shown in Table 3, the maximum and minimum pumpkin lateral diameters were $16.2 \mathrm{~cm}$ and $9.7 \mathrm{~cm}$ with fertilizer treatments $6\left(\mathrm{~N}_{2} \mathrm{P}_{2} \mathrm{~K}_{2}\right)$ and $1\left(\mathrm{~N}_{0} \mathrm{P}_{0} \mathrm{~K}\right)$, respectively. The maximum and minimum pumpkin longitudinal diameters were $10.4 \mathrm{~cm}$ and $7.6 \mathrm{~cm}$ with fertilizer treatments $6\left(\mathrm{~N}_{2} \mathrm{P}_{2} \mathrm{~K}_{2}\right)$ and $1\left(\mathrm{~N}_{0}\right.$ $\mathrm{P}_{0} \mathrm{~K}$ ), respectively. The most and least fruits per plant were 2.3 and 1.7 with treatments 6 $\left(\mathrm{N}_{2} \mathrm{P}_{2} \mathrm{~K}_{2}\right)$ and $1\left(\mathrm{~N}_{0} \mathrm{P}_{0} \mathrm{~K}\right)$, respectively. The heaviest individual fruit weighed $1.36 \mathrm{~kg}$ with treatment $6\left(\mathrm{~N}_{2} \mathrm{P}_{2} \mathrm{~K}_{2}\right)$, the second heaviest individual fruit weighed $1.35 \mathrm{~kg}$ with treatments $7\left(\mathrm{~N}_{2} \mathrm{P}_{3} \mathrm{~K}_{2}\right)$ and $10\left(\mathrm{~N}_{2} \mathrm{P}_{2} \mathrm{~K}_{3}\right)$, and the lightest individual fruit weighed $0.78 \mathrm{~kg}$ with treatment $1\left(\mathrm{~N}_{0} \mathrm{P}_{0} \mathrm{~K}\right)$. Plants grew more vigorously with fertilizer treatments $6\left(\mathrm{~N}_{2} \mathrm{P}_{2} \mathrm{~K}_{2}\right)$ and $10\left(\mathrm{~N}_{2} \mathrm{P}_{2} \mathrm{~K}_{3}\right)$. With these two treatments, the plants were tall and strong, the leaves were broad and green, and the size of the fruit was uniform. With fertilizer treatments $1\left(\mathrm{~N}_{0} \mathrm{P}_{0} \mathrm{~K}_{0}\right)$ and $2\left(\mathrm{~N}_{0} \mathrm{P}_{2} \mathrm{~K}_{2}\right)$, plant growth was relatively slow, leaves were small and yellow, the size of the fruit was uneven, fruit growth was slow, diseases were more prevalent, and effects of specific element deficiencies were more obvious.

As shown in Table 3, 'Jianbao' pumpkin yields were significantly different with different fertilizer treatments. Compared with the pumpkin yield that resulted without the use of any fertilizer application, the pumpkin yield with the use of fertilizers in any ratio was always higher. Among all 14 combinations of fertilizer applications, treatment 6 $\left(\mathrm{N}_{2} \mathrm{P}_{2} \mathrm{~K}_{2}\right)$ exhibited the highest pumpkin yield (30.4 tons $\left.\cdot \mathrm{ha}^{-1}\right)$; the second highest yield (29.9 tons $\cdot$ ha $^{-1}$ ) occurred with treatment $7\left(\mathrm{~N}_{2} \mathrm{P}_{3} \mathrm{~K}_{2}\right)$. Fertilizer treatment $1\left(\mathrm{~N}_{0} \mathrm{P}_{0} \mathrm{~K}_{0}\right)$ resulted in the lowest pumpkin yield (13.3 tons $\cdot \mathrm{ha}^{-1}$ ).

\section{Effect of specific fertilizer deficiency on pumpkin yield}

Our results showed that the treatment without any fertilizer resulted in the lowest yield. In comparison, treatment $6\left(\mathrm{~N}_{2} \mathrm{P}_{2} \mathrm{~K}_{2}\right)$ resulted in a relative yield of $43.8 \%$ and yield reduction rate of $56.2 \%$. When fertilization treatments were lacking in $\mathrm{N}\left(\mathrm{N}_{0} \mathrm{P}_{2} \mathrm{~K}_{2}\right), \mathrm{P}\left(\mathrm{N}_{2}\right.$ $\left.\mathrm{P}_{0} \mathrm{~K}_{2}\right)$, and $\mathrm{K}\left(\mathrm{N}_{2} \mathrm{P}_{2} \mathrm{~K}_{0}\right)$ fertilizer, the relative yields for treatment $6\left(\mathrm{~N}_{2} \mathrm{P}_{2} \mathrm{~K}_{2}\right)$ were $54.6 \%$, $75.3 \%$, and $65.5 \%$, respectively; the corresponding yield reduction rates were $45.4 \%$, $24.7 \%$, and $34.5 \%$, respectively (Table 4 ).

\section{Fertilization models and optimal fertilizer application}

Establishment of a single-factor performance equation model for $N$ fertilizer. The amount of $\mathrm{N}$ used in fertilizer treatments 2, 3, 6, and 11 and the corresponding pumpkin yields are shown in Fig. 1. A single-variable quadratic performance equation was calculated as $\mathrm{y}=$ $-0.0001 \mathrm{x}_{1}^{2}+0.0781 \mathrm{x}_{1}+16.51$. The relationship between the amount of $\mathrm{N}$ fertilizer used and the yield of 'Jianbao' pumpkin 
Table 3. Effects of fertilizer interactions on the yield and yield parameters of 'Jianbao' pumpkin.

\begin{tabular}{|c|c|c|c|c|c|c|}
\hline Treatment & $\begin{array}{c}\text { Fertilizer } \\
\text { combination }\end{array}$ & $\begin{array}{l}\text { Lateral diam }{ }^{\mathrm{z}} \\
\quad(\mathrm{cm})\end{array}$ & $\begin{array}{l}\text { Longitudinal } \\
\operatorname{diam}^{\mathrm{z}}(\mathrm{cm})\end{array}$ & $\begin{array}{l}\text { Number of fruits } \\
\text { per plant }\end{array}$ & $\begin{array}{l}\text { Avg single fruit } \\
\mathrm{wt}^{\mathrm{z}}(\mathrm{kg})\end{array}$ & Yield $^{\mathrm{z}}$ (tons $\cdot \mathrm{ha}^{-1}$ ) \\
\hline 2 & $\mathrm{~N}_{0} \mathrm{P}_{2} \mathrm{~K}_{2}$ & $11.4 \pm 0.06 \mathrm{~g}$ & $8.4 \pm 0.12 \mathrm{~g}$ & $1.8 \pm 0.17 \mathrm{de}$ & $0.92 \pm 0.03 \mathrm{~d}$ & $16.6 \pm 0.20 \mathrm{~h}$ \\
\hline 3 & $\mathrm{~N}_{1} \mathrm{P}_{2} \mathrm{~K}_{2}$ & $15.4 \pm 0.21 \mathrm{c}$ & $10.0 \pm 0.15 \mathrm{~cd}$ & $2.0 \pm 0.06 b c$ & $1.27 \pm 0.02 b$ & $25.5 \pm 0.77 \mathrm{de}$ \\
\hline 5 & $\mathrm{~N}_{2} \mathrm{P}_{1} \mathrm{~K}_{2}$ & $15.3 \pm 0.15 \mathrm{~cd}$ & $9.9 \pm 0.15 \mathrm{de}$ & $2.2 \pm 0.12 \mathrm{ab}$ & $1.26 \pm 0.04 \mathrm{~b}$ & $27.8 \pm 0.62 b$ \\
\hline 6 & $\mathrm{~N}_{2} \mathrm{P}_{2} \mathrm{~K}_{2}$ & $16.2 \pm 0.15 \mathrm{a}$ & $10.4 \pm 0.15 \mathrm{a}$ & $2.3 \pm 0.10 \mathrm{a}$ & $1.36 \pm 0.04 \mathrm{a}$ & $30.4 \pm 0.43 \mathrm{a}$ \\
\hline 7 & $\mathrm{~N}_{2} \mathrm{P}_{3} \mathrm{~K}_{2}$ & $16.1 \pm 0.15 \mathrm{ab}$ & $10.3 \pm 0.10 \mathrm{ab}$ & $2.2 \pm 0.12 \mathrm{ab}$ & $1.35 \pm 0.04 \mathrm{a}$ & $29.9 \pm 0.78 \mathrm{a}$ \\
\hline 10 & $\mathrm{~N}_{2} \mathrm{P}_{2} \mathrm{~K}_{3}$ & $16.0 \pm 0.15 \mathrm{ab}$ & $10.2 \pm 0.12 \mathrm{abc}$ & $2.2 \pm 0.15 \mathrm{ab}$ & $1.35 \pm 0.03 \mathrm{a}$ & $29.9 \pm 0.18 \mathrm{a}$ \\
\hline 11 & $\mathrm{~N}_{3} \mathrm{P}_{2} \mathrm{~K}_{2}$ & $15.9 \pm 0.10 b$ & $10.1 \pm 0.06 \mathrm{~cd}$ & $2.2 \pm 0.20 a b c$ & $1.34 \pm 0.05 \mathrm{a}$ & $29.5 \pm 0.17 \mathrm{a}$ \\
\hline 12 & $\mathrm{~N}_{1} \mathrm{P}_{1} \mathrm{~K}_{2}$ & $15.2 \pm 0.12 \mathrm{~d}$ & $9.8 \pm 0.10 \mathrm{e}$ & $2.1 \pm 0.06 \mathrm{bc}$ & $1.24 \pm 0.03 \mathrm{~b}$ & $26.1 \pm 0.76 \mathrm{~cd}$ \\
\hline 13 & $\mathrm{~N}_{1} \mathrm{P}_{2} \mathrm{~K}_{1}$ & $15.1 \pm 0.06 \mathrm{~d}$ & $9.8 \pm 0.12 \mathrm{e}$ & $2.0 \pm 0.17 \mathrm{~cd}$ & $1.25 \pm 0.04 \mathrm{~b}$ & $25.0 \pm 0.57 \mathrm{e}$ \\
\hline 14 & $\mathrm{~N}_{2} \mathrm{P}_{1} \mathrm{~K}_{1}$ & $15.3 \pm 0.10 \mathrm{~cd}$ & $9.9 \pm 0.12 \mathrm{de}$ & $2.1 \pm 0.06 \mathrm{abc}$ & $1.27 \pm 0.03 \mathrm{~b}$ & $26.7 \pm 0.45 \mathrm{c}$ \\
\hline
\end{tabular}

${ }^{\mathrm{z}}$ Different letters within the same column indicate that the difference was significant as determined by the least significant difference test $(P<0.05)$.

Table 4. Effects of element deficiency on 'Jianbao' pumpkin yield in different experimental fertilizer treatments.

\begin{tabular}{lcccc}
\hline Treatment & $\begin{array}{c}\text { Fertilizer } \\
\text { combination }\end{array}$ & Yield (tons·ha ${ }^{-1}$ ) & $\begin{array}{c}\text { Relative } \\
\text { yield (\%) }\end{array}$ & $\begin{array}{c}\text { Yield reduction } \\
\text { rate (\%) }\end{array}$ \\
\hline 1 & $\mathrm{~N}_{0} \mathrm{P}_{0} \mathrm{~K}_{0}$ & 13.3 & 43.8 & 56.2 \\
2 & $\mathrm{~N}_{0} \mathrm{P}_{2} \mathrm{~K}_{2}$ & 16.6 & 54.6 & 45.4 \\
4 & $\mathrm{~N}_{2} \mathrm{P}_{0} \mathrm{~K}_{2}$ & 22.9 & 75.3 & 24.7 \\
8 & $\mathrm{~N}_{2} \mathrm{P}_{2} \mathrm{~K}_{0}$ & 19.9 & 65.5 & 34.5 \\
6 & $\mathrm{~N}_{2} \mathrm{P}_{2} \mathrm{~K}_{2}$ & 30.4 & 100.0 & - \\
\hline
\end{tabular}

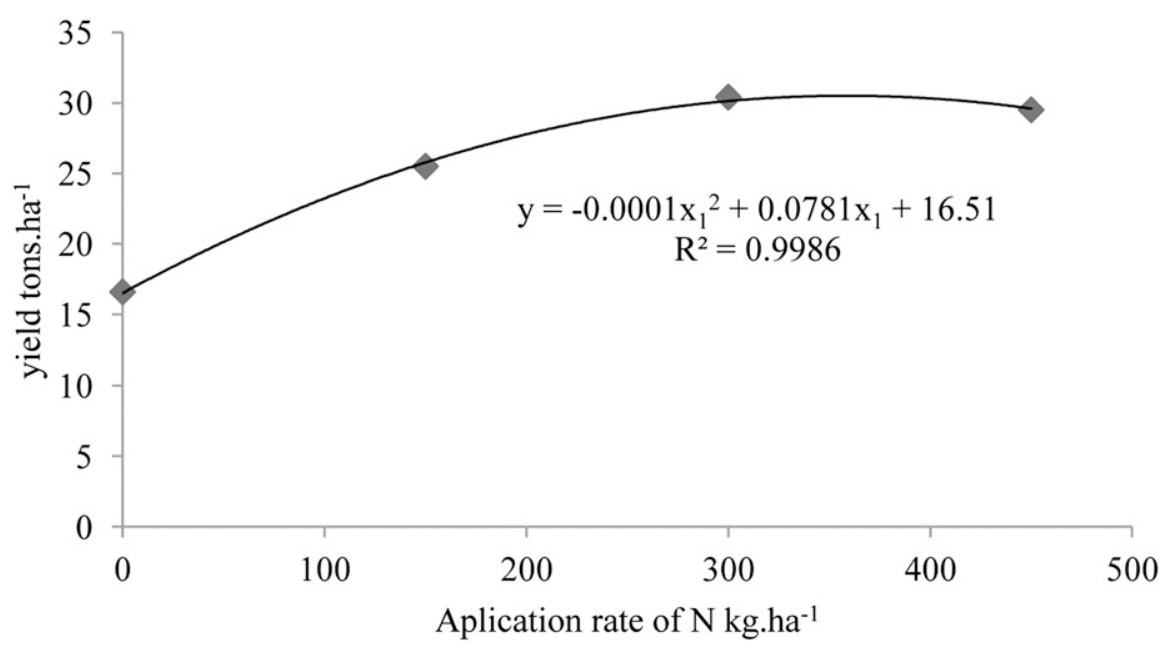

Fig. 1. Relationship between the application rate of $\mathrm{N}$ fertilizer and 'Jianbao' pumpkin yield. The data points 2, 3, 6, and 11 represent fertilizer treatments with four different $\mathrm{N}$ application levels; $\mathrm{N}_{0} \mathrm{P}_{2} \mathrm{~K}_{2}, \mathrm{~N}_{1}$ $\mathrm{P}_{2} \mathrm{~K}_{2}, \mathrm{~N}_{2} \mathrm{P}_{2} \mathrm{~K}_{2}$, and $\mathrm{N}_{3} \mathrm{P}_{2} \mathrm{~K}_{2}$, respectively (as shown in Table 1).

was significant $(P<0.05)$. Keeping the levels of $\mathrm{P}$ and $\mathrm{K}$ (i.e., $\mathrm{P}_{2} \mathrm{~K}_{2}$ ) constant and increasing the amount of $\mathrm{N}$ in the fertilizer resulted in an increase in yield. However, when the amount of $\mathrm{N}$ in the fertilizer exceeded $390.5 \mathrm{~kg} \cdot \mathrm{ha}^{-1}$, the yield decreased with further increases in the $\mathrm{N}$ content. The highest 'Jianbao' pumpkin yield of 31.8 tons $\cdot \mathrm{ha}^{-1}$ was obtained when the amount of $\mathrm{N}$ in the fertilizer reached $390.5 \mathrm{~kg} \cdot \mathrm{ha}^{-1}$ (Fig. 1).

Establishment of a single-factor performance equation model for $P$ fertilizer. By analyzing the amount of $\mathrm{P}$ used in the fertilizer with treatments $4,5,6$, and 7 and the corresponding pumpkin yield, a single-variable quadratic performance equation was calculated as $\mathrm{y}=-0.0002 \mathrm{x}_{2}^{2}+0.0855 \mathrm{x}_{2}+22.86$ (as shown in Fig. 2). The relationship between the use of $\mathrm{P}$ fertilizer and the yield of 'Jianbao' pumpkin was significant $(P<$ $0.05)$. Keeping the levels of $\mathrm{N}$ and $\mathrm{K}$ constant (i.e., $\mathrm{N}_{2} \mathrm{~K}_{2}$ ) and increasing the amount of $\mathrm{P}$ in the fertilizer resulted in an increase in yield; however, the rate of increase was relatively exceeded $213.8 \mathrm{~kg} \cdot \mathrm{ha}^{-1}$, the yield decreased with further increases in the $\mathrm{P}$ content. The highest 'Jianbao' pumpkin yield of 32.0 tons $\cdot \mathrm{ha}^{-1}$ was obtained when the amount of $\mathrm{P}$ in the fertilizer reached $213.8 \mathrm{~kg} \cdot \mathrm{ha}^{-1}$ (Fig. 2).

Establishment of a single-factor performance equation model for $K$ fertilizer. By analyzing the small. When the amount of $\mathrm{P}$ in the fertilizer amount of $\mathrm{K}$ used in the fertilizer with treatments $6,8,9$, and 10 and the corresponding pumpkin yield, a single-variable quadratic performance equation was calculated as $\mathrm{y}=-8 \mathrm{E}-05 \mathrm{x}_{3}{ }^{2}+$ $0.0594 x_{3}+19.86$ (as shown in Fig. 3). The relationship between the use of $\mathrm{K}$ fertilizer and the yield of 'Jianbao' pumpkin was significant $(P<0.05)$. When the levels of $\mathrm{N}$ and $\mathrm{P}$ were constant (i.e., $\mathrm{N}_{2} \mathrm{P}_{2}$ ), increasing the amount of $\mathrm{K}$ in the fertilizer resulted in an increase in yield. When the amount of $\mathrm{K}$ in the fertilizer exceeded $371.3 \mathrm{~kg} \cdot \mathrm{ha}^{-1}$, the yield decreased with further increases in the K content. The highest 'Jianbao' pumpkin yield of 30.9 tons $\cdot$ ha $^{-1}$ was obtained when the amount of $\mathrm{K}$ in the fertilizer reached $371.3 \mathrm{~kg} \cdot \mathrm{ha}^{-1}$ (Fig. 3).

Performance equation describing the effects of $N, P$, and $K$ fertilizers. By analyzing 'Jianbao' pumpkin yields obtained with the 14 fertilizer treatments with different $\mathrm{N}, \mathrm{P}$, and $\mathrm{K}$ ratios, a ternary performance function was calculated as $\mathrm{y}=13.4481+0.0462 \mathrm{x}_{1}$ $0.0001 \mathrm{x}_{1}^{2}+0.0275 \mathrm{x}_{2}-0.0003 \mathrm{x}_{2}^{2}+0.0317 \mathrm{x}_{3}-$ $0.0001 \mathrm{x}_{3}^{2}+0.0001 \mathrm{x}_{1} \mathrm{x}_{2}+0.0001 \mathrm{x}_{1} \mathrm{x}_{3}$. The relationship between different $\mathrm{N}, \mathrm{P}$, and $\mathrm{K}$ fertilizer treatments and the yield of 'Jianbao' pumpkin was not significant $\left(R^{2}=0.99 ; \mathrm{F}=\right.$ $62.7 ; P>0.05)$. Therefore, the ternary quadratic equation failed to provide a successful fit for fertilizer performance.

\section{Discussion}

Our study is distinct from previous studies conducted by Huang et al. (2006), Li et al. (2013), and Liu et al. (2014) for two reasons. First, the experimental plant used in these studies was $C$. moschata, but we used a new species, C. maxima, named 'Jianbao' (bred by the authors), as the experimental plant. Few studies have analyzed the fertilization of C. maxima using soil testing and fertilizer recommendation techniques. Second, the studies by Huang et al. (2006) and Liu et al. (2014) emphasized the use of the fertilization technique for cultivating pumpkin in northern semi-arid regions, whereas the study by $\mathrm{Li}$ et al. (2013) investigated the balanced fertilization technique for cultivating edible pumpkins in the northwestern plateau of Hebei, China. Our study provides the first analysis of a fertilization technique for cultivating 


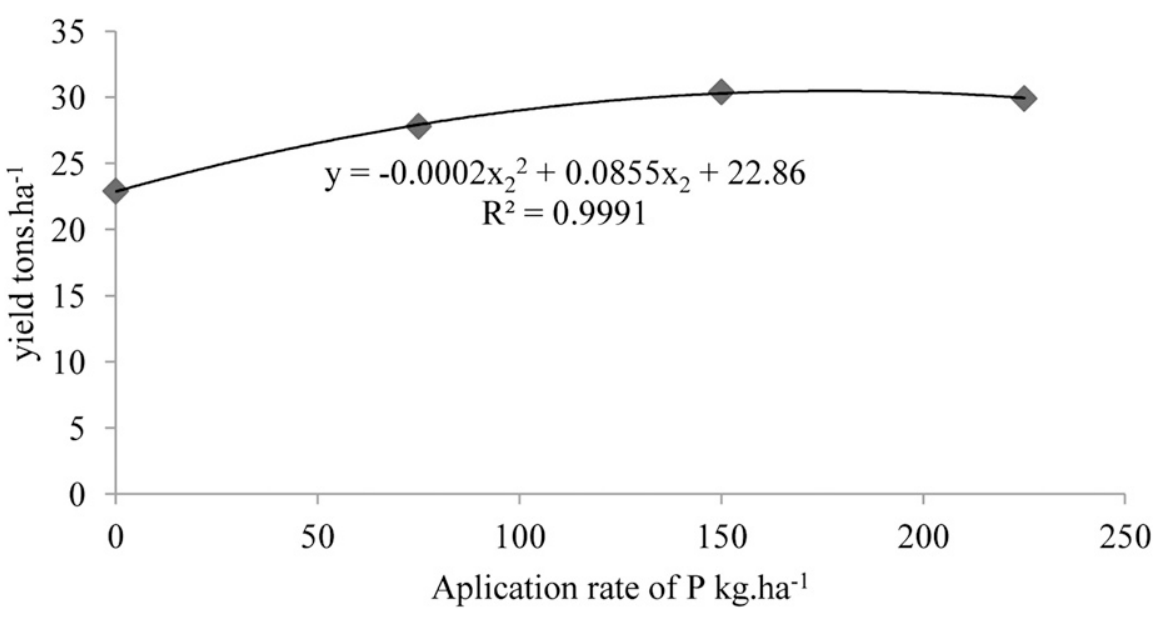

Fig. 2. Relationship between the application rate of $\mathrm{P}$ fertilizer and 'Jianbao' pumpkin yield. The data points 4, 5, 6, and 7 represent fertilizer treatments with four different $P$ application levels: $\mathrm{N}_{2} \mathrm{P}_{0} \mathrm{~K}_{2}, \mathrm{~N}_{2}$ $\mathrm{P}_{1} \mathrm{~K}_{2}, \mathrm{~N}_{2} \mathrm{P}_{2} \mathrm{~K}_{2}$, and $\mathrm{N}_{2} \mathrm{P}_{3} \mathrm{~K}_{2}$, respectively (as shown in Table 1).

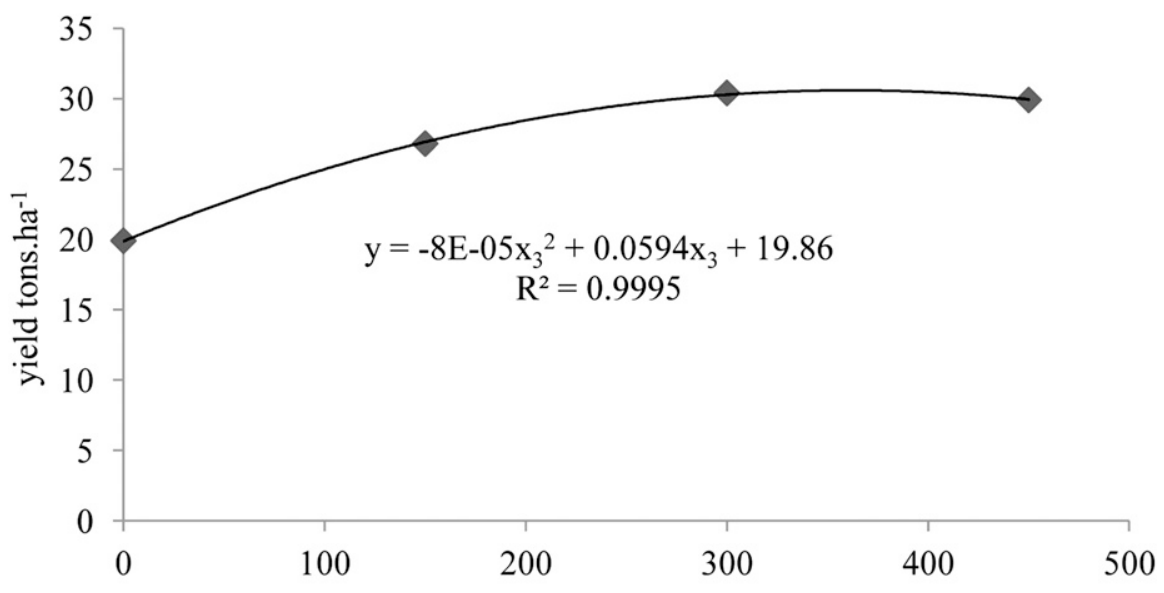

Aplication rate of $\mathrm{K} \mathrm{kg} \cdot \mathrm{ha}^{-1}$

Fig. 3. Relationship between the application rate of $\mathrm{K}$ fertilizer and 'Jianbao' pumpkin yield. The data points $6,8,9$, and 10 represent fertilizer treatments with four different $\mathrm{K}$ application levels: $\mathrm{N}_{2} \mathrm{P}_{2} \mathrm{~K}_{0}, \mathrm{~N}_{2}$ $\mathrm{P}_{2} \mathrm{~K}_{1}, \mathrm{~N}_{2} \mathrm{P}_{2} \mathrm{~K}_{2}$, and $\mathrm{N}_{2} \mathrm{P}_{2} \mathrm{~K}_{3}$, respectively (as shown in Table 1).

C. maxima in southern Fujian using the soil testing and fertilizer recommendation methods. The results of this study are expected to contribute to the promotion of large-scale cultivation of $C$. maxima in the southern regions of China.

The accurate classification of soil fertility is critical to successful fertilization using the soil testing and fertilizer recommendation methods (Fageria and Baligar, 1997). The relative yield associated with a fertilizer lacking a specific element is a key parameter for establishing a soil fertility reading indicator (Cope and Evans, 1985). Huang (2003) classified effective nutrients in the soil into five levels based on the relative yield of wheat obtained when applying a fertilizer lacking a specific element. Lin and Zhao (1987) used relative yields of $50 \%, 70 \%$, $90 \%$, and $95 \%$ of wheat cultivated with a fertilizer lacking $\mathrm{P}$ to classify the effective $\mathrm{P}$ fertility of the soil. Other scholars have classified soil fertility based on the relative yield. For example, Cope and Evans (1985) classified soil fertility based on the standards of $50 \%, 75 \%$, and $100 \%$ relative yields. Sun et al. (2009) determined P and K fertility of the soil based on the following criterion: extremely high, high, medium, and low if the relative yield is greater than $95 \%$, between $90 \%$ and $95 \%$, between $70 \%$ and $90 \%$, and less than $75 \%$, respectively. The same criterion has been used by Yang et al. (2011) for classifying $P$ fertility of the soil. However, the study by Chen and Zhang (2006) proposed a different criterion for grading the level of nutrients of major elements in the soil: high, medium, low, and extremely low if the relative yield is greater than $95 \%$, between $75 \%$ and $95 \%$, between $50 \%$ and $75 \%$, and less than $50 \%$, respectively. Using the principle of this criterion, the fertility levels of alkaline $\mathrm{N}$, effective $\mathrm{P}$, and available $\mathrm{K}$ were low, medium, and medium, respectively, for the soil in our experimental field. The interaction between $\mathrm{N}, \mathrm{P}$, and $\mathrm{K}$ fertilizers rates and soil nutrient abundance affects the final yield differently. Based on the performance of pumpkins plants that received fertilizer treatments lacking $\mathrm{N}, \mathrm{P}$, and $\mathrm{K}$, we suggest that the importance of fertilizer components follows the order of $\mathrm{N}>\mathrm{K}>\mathrm{P}$.

The experimental design based on the "3414" scheme exhibited several advantages, including less regression, optimal design, high efficiency, high comparability, and ease of demonstration and promotion. These merits satisfy the professional requirements for fertilizer testing and fertilization decisions. Therefore, this test scheme has been widely used for designing soil testing and fertilizer recommendation plans by domestic and international researchers (Wang et al., 2002; Zhang et al., 2016). Wang et al. (2018) adopted the same test plan for analyzing the nutrient requirements and application rates of $\mathrm{N}, \mathrm{P}$, and $\mathrm{K}$ for spring corn cultivated in Jilin, and they found that the growth of spring corn was highly dependent on nutrients in the fertilizer, where the yield could be improved by $42 \%$, on average, with effective fertilization. Zeng et al. (2017) also used the same test plan to analyze the effects of fertilization on the yield and quality of honeysuckle. They found that $\mathrm{P}$ fertilizer was the key element affecting bud growth, and that chlorogenic acid content was positively correlated with the phosphate content in the fertilizer. They also revealed a positive relationship between luteolin content in xylophone and the synergistic effects of $\mathrm{P}$ and $\mathrm{K}$ fertilizers. These findings provide a practical basis for performing rational $\mathrm{N}$ and $\mathrm{P}$ fertilization of honeysuckle.

Mao et al. (2014) explored the fertilization technology system for rice cultivation in Jiangdu, Jiangsu, by using the soil testing and fertilizer recommendation methods. More specifically, they recommended different ratios of N, P, and $\mathrm{K}$ fertilizers for different soil fertility conditions. Their results demonstrated the feasibility of establishing a fertilization technology system based on the test data. Although the " 3414 " test design has been widely used and has the capability of generating important information, its application is limited by multicollinearity, heteroscedasticity, and unreasonable professional assumptions in the fertilization model (Zhang et al., 2016). In addition, because it is challenging to control and test the management abilities of the personnel performing the field experiments, the success rate of fitting the fertilization data with a statistical model can be quite low. For example, Wang et al. (2002) performed 27 " 3414 " winter wheat tests in Tangshan, Hebei; however, the success rate of obtaining a good-fitting model from the experimental data was only $56 \%$ in their case. Sun et al. (2009) also used the "3414" test plan to analyze the cultivation of winter wheat in Shandong; however, the success rate for fitting the experimental data with a ternary quadratic model was only $9 \%$ in their case. Yang et al. (2011) used the " 3414 " test plan to analyze the ratio of different elements in the fertilizer for cultivating rapeseed; however, they were only able to fit the experimental data to a ternary quadratic model with a $19.6 \%$ 
success rate. In our study, statistical fitting of a ternary quadratic fertilizer performance model was not successful because the regression relationship of the fitting function was not significant. In our study, the experiment was conducted for one growing season only, and the experiment was restricted to Yingshan village in Dehua. Therefore, only limited experimental data were obtained, which may have affected the success rate of statistical fitting to a ternary quadratic fertilizer model. The "3414" test plan can be used to construct not only a ternary quadratic fertilizer performance regression equation but also a binary or single-variable fertilizer performance regression equation. We could extract valuable information for determining a fertilization strategy and improving the field fertilization experimental efficiency. In our experiment, all the single-variable quadratic fertilizer regression equations were significant. Therefore, statistical fitting of a single-variable quadratic fertilizer equation can complement and optimize the fitting of a ternary quadratic model. It also provides an important reference for realizing balanced fertilization of pumpkin.

\section{Conclusions}

The analysis of the single-variable quadratic fertilizer performance function revealed a significant relationship between the amount of N, P, K used in the fertilizer and the yield of 'Jianbao' pumpkin. Our regression model showed that when the amount of $\mathrm{N}, \mathrm{P}$, and $\mathrm{K}$ were increased in the fertilizer, the yield of 'Jianbao' pumpkin increased. However, when the application rate of these elements exceeded a certain threshold value, further increases in the amount used in the fertilizer resulted in a reduction in pumpkin yield. Based on the regression equations, the recommended compositions of $\mathrm{N}, \mathrm{P}$, and $\mathrm{K}$ fertilizers per hectare for the 'Jianbao' pumpkin are $390.5,213.8$, and $371.3 \mathrm{~kg}$, respectively.

\section{Literature Cited}

Chai, Y., Y. Chen, X. Xia, and M. Wang. 2014. Life cycle analysis of environmental benefits through demonstration of the soil testing and formula fertilization project A case study in maize production in Liaocheng City, Shandong Province. J. Plant Nutr. Fert. 22:229-236.

Chai, Z., X. Wang, P. Jiang, J. Sheng, and L. Sheng. 2013. Influence on growth and yield of korla fragrant pear under different treatments $\mathrm{N}, \mathrm{P}$, K. J. Nucl. Agr. Sci. 27:1048-1053.

Chen, X. and F. Zhang. 2006. Establishing the technical index system of formula fertilization for soil testing by "3414" experiment. China Agr. Technol. Ext. 26:36-39.

Chu, P., C. Xiang, C. Zhang, and C. Liu. 2007. Genetic diversity of Cucurbita moschata genotypes revealed by RAPD markers and agronomic traits. J. Nucl. Agr. Sci. 21:441-446.

Cope, J.T. and C.E. Evans. 1985. Soil Testing. Adv. Soil Sci. 1:201-228.

Fageria, N.K. and V.C. Baligar. 1997. Response of common bean, upland rice, corn, wheat, and soybean to soil fertility of an Oxisol. J. Plant Nutr. 20:1279-1289.

Gao, W., H. Zheng, F. Gao, and M. Fan. 2018. The status and evaluation of formula fertilization by soil testing technology on maize nutrition management in Tongliao of Inner Mongolia. J. Plant Nutr. Fert. 24:544-552.

Han, X. and X. Zhang. 2014. Status and changing trend of soil nutrient contents in cultivated land from the implementation of soil test and formula fertilization in Wuhu county Anhui Province. Chin. J. Soil Sci. 45:892-899.

Huang, D. 2003. Soil testing and fertilizer recommendations in China during the past decade. J. Plant Nutr. Fert. 9:495-499.

Huang, W., J. Zhang, F. Yang, and L. Zhang. 2006. Effect of potassium nutrition on yield and store characteristic of small cushaw in solar greenhouse. Soil Fert. Sci. China 4:43-45.

Li, H., Y. Zhao, L. Wang, L. Zhang, and X. Bian. 2013. Study on balanced fertilization of pumpkins in northwest plateau of Hebei Province. Northern Hort. 13:197-199.

Li, J., M. Zhang, Q. Kong, B. Yao, and D. Liu. 2017. Building fertilization categories of N, P and $\mathrm{K}$ fertilization for early rice using systematic clustering method in county territory. J. Plant Nutr. Fert. 23:531-538.

Lin, S., and S. Zhao. 1987. Study on nutrient abundance index and fertilization in tidal soil. Shan Dong Agr. Sci 5:25-27, 40.
Liu, S., H. Cao, J. Zhang, and X. Hu. 2014. Effects of different water and nitrogen supplies on root growth, yield and water and nitrogen use efficiency of small pumpkin. Sci. Agr. Sin. 47:1362-1371.

Mao, W., W. Li, B. Tang, H. Zeng, F. Zhang, and H. Gao. 2014. Study on index system for soil testing and formulated fertilization: A case study of rice of Jiangdu City in Jiangsu Province. J. Plant Nutr. Fert. 22:396-406.

Sun, J., D. Wei, X. Ma, D. Liu, W. Guo, X. Liu, and W. Lu. 2013. Establishing fertilization recommendation index of soybean in black soil region of Heilongjiang Province. Soybean Sci. 32:512-516.

Sun, Y., Y. Guo, S. Yu, Q. Jiang, L. Cheng, Z. Cui, X. Chen, R. Jiang, and F. Zhang. 2009. Establishing phosphorus and potassium fertilization recommendation index based on the ' 3414 ' field experiments. J. Plant Nutr. Fert. 17:197203.

Tang, Q. 2005. Data Processing System DPS 7.05. Wang, M. 2002. Genus Cucurbita-The most diversity. J. China Watermelon Melon 3:42-45.

Wang, S., X. Chen, X. Gao, D. Mao, and F. Zhang. 2002. Study on simulation of " 3414 " fertilizer experiments. J. Plant Nutr. Fert. 8:409-413.

Wang, Y., Q. Gao, G. Feng, L. Yan, C. Li, L.X. Song, Z. Liu, and J. Fang. 2018. N, P and K requirement and fertilizer use efficiencies of spring maize in Jilin Province. J. Plant Nutr. Fert. 24:306-315.

Yang, H., Y. Li, C. Wang, G. Liang, J. Wang, and X. Liu. 2016. Correlation and regression analysis of taste evaluation and nutrient components in squash. China Veg. 11:25-32.

Yang, L., Y. Bai, H. Wang, L. Wang, Y. Lu, and G. Wu. 2011. Application of "3414" field trial design for establishing soil testing and fertilizer recommendation index. J. Plant Nutr. Fert. 17:1018-1023.

Zeng, H., X. Wang, Z. Qiao, Y. Li, N. Cai, S. Liu, and Y. Li. 2017. Influence on yield and quality of Lonicera japonica by soil testing and formulated fertilization. J. Nucl. Agr. Sci. 31:2443-2449.

Zhang, M., J. Li, Q. Kong, and F. Yan. 2016 Progress and prospect of the study on cropresponse-to-fertilization function model. Acta Pedol. Sin. 53:1343-1356. 